\title{
Acumulação flexível em questão: uma análise a partir da Ambev Cervejaria Rio de Janeiro, Campo Grande, Rio de Janeiro - RJ
}

L'accumulation flexible en question: une analyse d'Ambev Cervejaria Rio de Janeiro, Campo Grande, Rio de Janeiro - RJ Acumulación Flexible en cuestión: un análisis a partir de la Ambev Cervejaria Rio De Janeiro, Campo Grande, Rio De Janeiro RJ Flexible accumulation in question: an analysis of Ambev Cervejaria Rio de Janeiro, Campo Grande, Rio de Janeiro - RJ.

\section{Beatriz do Nascimento Sant'Anna}

\section{OpenEdition}

Journals

\section{Edição electrónica}

URL: http://journals.openedition.org/espacoeconomia/16767

DOI: 10.4000/espacoeconomia.16767

ISSN: 2317-7837

\section{Editora}

Núcleo de Pesquisa Espaço \& Economia

Refêrencia eletrónica

Beatriz do Nascimento Sant'Anna, « Acumulação flexível em questão: uma análise a partir da Ambev Cervejaria Rio de Janeiro, Campo Grande, Rio de Janeiro - RJ », Espaço e Economia [Online], 19 | 2020, posto online no dia 01 setembro 2020, consultado o 09 setembro 2020. URL : http:// journals.openedition.org/espacoeconomia/16767; DOI : https://doi.org/10.4000/espacoeconomia 16767

Este documento foi criado de forma automática no dia 9 setembro 2020.

(C) NUPEE 


\section{Acumulação flexível em questão: uma análise a partir da Ambev Cervejaria Rio de Janeiro, Campo Grande, Rio de Janeiro - RJ}

L'accumulation flexible en question : une analyse d'Ambev Cervejaria Rio de Janeiro, Campo Grande, Rio de Janeiro - RJ

Acumulación Flexible en cuestión: un análisis a partir de la Ambev Cervejaria

Rio De Janeiro, Campo Grande, Rio De Janeiro RJ

Flexible accumulation in question: an analysis of Ambev Cervejaria Rio de

Janeiro, Campo Grande, Rio de Janeiro - RJ.

\section{Beatriz do Nascimento Sant'Anna}

\section{Introdução}

1 A cerveja possui um caráter social muito expressivo para o povo brasileiro, mostrandose como uma espécie de anestesia às mazelas enfrentadas diariamente por uma sociedade que convive com números elevados de desigualdade social, desemprego, insuficiência na disponibilidade de serviços básicos como saúde, educação e transporte. Assim como o futebol, a cerveja se apresenta como uma válvula de escape ao cotidiano, trazendo alegria, mesmo que momentânea, e reunindo grupos sociais e famílias. Apesar de estar havendo um aumento expressivo no consumo de cervejas artesanais e bebidas especiais, as cervejas mais baratas ainda são as mais consumidas e procuradas, fato que evidencia que as grandes massas populacionais correspondem ao carro-chefe do mercado consumidor. Essa massa é formada pelos trabalhadores formais e informais que enfrentam todos os dias uma rotina cansativa e encontram na bebida, uma forma de "desestressar". 
2 Entender seu processo produtivo e sua expansão a partir da maior cervejaria do mundo nos permite uma vasta gama de possibilidades de análise das ramificações existentes desse segmento. A Ambev é detentora de uma porcentagem tão abundante do mercado cervejeiro que nos permite levantar inúmeras questões sobre concorrência, já que a cervejaria possui mais de 200 rótulos de bebidas em seu portfólio. Além disso, a empresa possui uma política ávida de alcance de metas e mercado consumidor, embasada em marketing pesado e gestão de pessoas. Todos estes fatores a fazem ser uma multinacional de peso que possui um claro padrão de flexibilidade, seja nas dinâmicas produtivas pautadas em uma economia de escopo, seja no processo global de reestruturação territorial-produtiva que muda a dinâmica espacial e da força de trabalho produtiva, para atender aos interesses do capital.

3 A cervejaria está localizada em Campo Grande, bairro da Zona Oeste do Rio de Janeiro, com 119,13 $\mathrm{km}^{2}$, cerca de trezentos e trinta mil habitantes, sendo considerado o mais populoso bairro do município do Rio de Janeiro, como também o mais populoso do Brasil (Censo 2010). Situada nos limites do bairro de Campo Grande no Rio de Janeiro-RJ com o município de Nova Iguaçu-RJ, a filial da Ambev, Cervejaria Rio de Janeiro, é um importante braço da gigante do ramo cervejeiro, destacada como a maior da América do Sul. Localizada na antiga estrada Rio-São Paulo, atual BR-465, nº 6011, Km 31, foi inaugurada em 1996 (inicialmente apenas como Antártica) e hoje é uma das maiores do mundo. Essa filial produz rótulos da Antártica, Skol, Brahma e Bohemia, além de possuir sua própria fábrica de vidros, inaugurada em 2008, para produção de garrafas de cerveja long neck.

4 As informações coletadas sobre a filial em análise foram obtidas em trabalho de campo realizado em setembro de 2019, através do Tour Beer Lovers onde o público em geral, mediante agendamento prévio no site da cervejaria, pode ter acesso a uma visita guiada nas dependências de alguma filial que esteja disponível para visitação.

5 A filial consiste em uma fábrica, um centro de distribuição e de vendas, e movimenta, segundo informações oficiais obtidas em trabalho de campo, aproximadamente 700 milhões de reais/ano. A empresa possui uma política pautada, segundo o próprio responsável pela visitação, na meritocracia em relação às carreiras e aposta em um ambiente de trabalho mais informalizado.

6 Em relação à localização da Cervejaria, o fator de maior relevância para a escolha do local foi a disponibilidade de água, a fábrica está sediada na Região Hidrográfica II, de atuação e responsabilidade do Comitê Guandu-RJ. A empresa capta cerca de $12 \mathrm{mil} \mathrm{m}^{3}$ de água por dia do Rio Guandu Mirim, que faz parte da Bacia do Guandu.

\section{Acumulação flexível e reestruturação territorial- produtiva}

7 Fordismo e acumulação flexível (ou pós-fordismo, produção flexível etc.) se entrelaçam constantemente em suas definições. Portanto, fazer periodizações bem delimitadas de seus processos característicos e históricos é algo limitador. As tendências que por muito se entendem de caráter pós-fordista são fenômenos que já ocorriam no início do fordismo (até antes do fordismo), sofrendo algumas modificações; porém, tais modificações foram suficientemente significativas para a reprodução capitalista, com a emergência de um novo modelo, mas não tão novo assim, que apresentou algumas 
inovações na sua atuação. Especialmente na sua "flexibilidade", que mudou as dinâmicas de consumo, produção e comportamento social como um todo.

Assim como na transição do fordismo para a acumulação flexível - suas características se entrelaçam em relação ao seu modus operandi, sendo o segundo, produto aperfeiçoado do primeiro -, no fordismo as inovações tecnológicas e organizacionais foram extensão de tendências já estabelecidas, como a onda de fusões, formação de monopólios, criação de carteis, relações hierárquicas delimitadas, entre outros.

A expressão "capitalismo flexível” descreve hoje um sistema que é mais que uma variação sobre um velho tema. Enfatiza-se a flexibilidade. Atacam-se as formas rígidas de burocracia, e também os males da rotina cega. Pede-se aos trabalhadores que sejam ágeis, estejam abertos a mudanças a curto prazo, assumam riscos continuamente, dependam cada vez menos de leis e procedimentos formais. (SENNETT, p. 10, 1999)

Segundo Harvey, o período caracterizado como Acumulação Flexível se caracteriza pelo confronto direto com a rigidez do fordismo. E as principais características são as flexibilizações dos processos de trabalho, dos mercados de trabalho, dos produtos e padrões de consumo. Nas regiões que anteriormente careciam de tradição industrial, os focos de acumulação flexível foram desestruturando o trabalho organizado. Implicando um nível relativo alto de desemprego "estrutural", ganhos de salários reais modestos e o retrocesso do poder sindical (que era um dos principais pilares políticos da estrutura fordista).

Os arranjos flexíveis dos mercados de trabalho, à primeira vista, podem não criar uma insatisfação, já que poderiam trazer por vezes benefícios mútuos. No entanto, de maneira geral, não podemos ver como algo positivo para o trabalhador, considerando as variáveis: cobertura de seguro, direitos de pensão, níveis salariais e a segurança no emprego. Gerando uma onda de subcontratação ou trabalho temporário, onde se destaca a presença cada vez maior de uma força de trabalho flutuante, que pode ser demitida em caso de uma crise inesperada.

11 Esse novo regime de acumulação gerou também desenvolvimento desigual nos setores, com o crescimento do setor de serviços, e nas diferentes regiões geográficas, com a chegada de novos conjuntos industriais em países recém-industrializados. Produzindo uma nova lógica espacial com inovações em transportes que reduzem as distâncias através de uma diminuição do tempo de traslado, e a crescente aceleração das trocas de informação.

12 Essa transição para a acumulação flexível nem sempre se dava de maneira simples, devido à ênfase na solução de problemas, nas respostas rápidas e na maioria das vezes altamente especializadas, levando em conta a adaptação para propósitos específicos. A mudança com relação à produção se dá nas economias de escala, antes buscada no modo de produção fordista, mas que agora fora derrotada pelas economias de escopo, pela sua rapidez em atender as novas tendências.

Desta forma, essa mudança foi possibilitada pela crescente capacidade da manufatura de ter uma variedade de bens em pequenos lotes e por menores preços, atendendo uma gama maior de produtos. Uma das mudanças citadas com relação às novas formas de organização de estoque foi o conceito "just-in-time", que consiste em produzir no tempo certo, na quantidade exata, com uma quantidade de trabalho certa, diminuindo consideravelmente a quantidade de material necessária para manter a fluidez da produção. 
14 A flexibilização alterou não somente as dinâmicas produtivas, mas também aumentou o ritmo para os produtos, alterando o tempo de giro dessas mercadorias e se tornando um importante elemento para a lucratividade capitalista. No entanto, a redução do tempo de giro não surtiria efeito sem o aumento do consumo. A partir disso observa-se a crescente introdução das modas fugazes - que aumentou consideravelmente os empregos no setor terciário - e a mercantilização de culturas locais como características fortes do pós-modernismo.

15 A desregulamentação, forte aspecto da acumulação flexível, resultou muitas vezes em um aumento do monopólio. A onda de fusões e de diversificações corporativas, afastou cada vez mais os empregados da linha primária de negócios de suas empresas, pois a sua função principal se tornou gerar dinheiro e não o produto final. o capitalismo ampliou o processo de dispersão, mobilidade geográfica e de respostas flexíveis no mercado de trabalho e no consumo, sempre respaldado por uma forte carga de inovação tecnológica e institucional.

o interesse pelo conhecimento científico e técnico se mostrou extremamente importante num mundo onde as mudanças estão cada vez mais aceleradas e com isso tem-se a necessidade de estar por dentro da última tecnologia e da última tendência para que se tenha posição de vantagem no mercado competitivo. O conhecimento ganha valor de mercadoria, gerando uma produção organizada de conhecimento com fins bem delimitados.

17 O Estado é chamado para regular as atividades do capital corporativo no interesse na nação, ao mesmo tempo, fica a cargo de criar um ambiente propício aos negócios afim de atrair capital financeiro transnacional e global com a justificativa de conter a fuga de capital em um ataque especulativo. Entendemos com isso que, ao criar um ambiente benéfico aos negócios, por exemplo, oferecendo incentivos fiscais, os governos acabam ficando à mercê das transnacionais, pois em uma situação em que estas encontrem regiões mais favoráveis, simplesmente retiram-se. Desta forma os governos ficam em uma situação delicada, pois ao mesmo tempo em que deveriam resguardar os direitos dos trabalhadores, entendem que seria extremamente impopular a perda de uma grande transnacional. Por esse motivo estas migram, no período da acumulação flexível, para países onde a classe trabalhadora não esteja muito organizada, e que, portanto, não tenham muitas conquistas, como é o caso dos países periféricos.

Reestruturação, no sentido mais amplo, transmite a noção de uma "freada", senão de uma ruptura nas tendências seculares, e de uma mudança em direção a uma ordem e uma configuração significativamente diferentes da vida social, econômica e política. Evoca, pois, uma combinação sequencial de desmoronamento e reconstrução, de desconstrução e tentativa de reconstituição, proveniente de algumas deficiências ou perturbações nos sistemas de pensamento e ação aceitos. A antiga ordem está suficientemente esgarçada para impedir os remendos adaptativos convencionais e exigir, em vez deles, uma expressiva mudança estrutural (SOJA, 1993, p. 82).

O desenvolvimento capitalista precisa negociar uma margem estreitíssima entre a preservação dos valores dos compromissos passados, assumidos num lugar e num tempo específicos, ou sua desvalorização, a fim de abrir um novo espaço para a acumulação. O capitalismo luta perpetuamente, portanto, por criar uma paisagem social e física à sua própria imagem, e indispensável para suas necessidades em determinado ponto do tempo, simplesmente para, com igual certeza, minar, desintegrar e até destruir essa paisagem, num ponto posterior do tempo. As contradições internas do capitalismo expressam-se através da formação e 
reformação irrequietas das paisagens geográficas. É de acordo com essa música que a geografia histórica do capitalismo tem que dançar, ininterruptamente. (HARVEY, 1985, p.150)

19 A espacialização dessa reestruturação, dessa nova maneira organizacional dos sistemas produtivos e da vida social, pode ser observada nas economias urbana e regional, a sobreposição de forma hierarquizada de desenvolvimento e subdesenvolvimento de diferentes regiões, setores e empresas, alargamento da divisão do trabalho, abertura de novos mercados, expansão geográfica na busca por mão de obra e matéria prima mais baratas etc.

Soja (1993) enumera algumas características principais da reestruturação contemporânea, com impacto espacializante, principalmente a partir da década de 1980. Sendo oportuno dar ênfase à:

21 [a] Tendência cada vez mais maior de formação de concentrações capitalistas a partir dos conglomerados empresariais que concentram desde uma produção industrial diversificada à entretenimento. A formação desses conglomerados perpassa as fusões e monopólios nos moldes do fordismo, agora se observa uma maior flexibilidade dos processos produtivos que atuam em localizações diferentes, produção paralela;

[b] Maior aparato tecnológico nas atividades industriais, de pesquisa e serviços. 0 alcance espacial desses sistemas de produção mais informatizado ganhou caráter mundial, mas também teve poderosa influência na urbanização de lugares que até então não apresentavam industrialização do tipo fordista - com menor restrição territorial de controle estatal - gerando um contrassenso de (des)concentração e (re)concentração na paisagem geográfica. Como resultado, o capital doméstico perde sua força nas economias locais e nacionais conforme a internacionalização dessas economias cresce;

[c] O resultado do esmorecimento dos controles locais e regulação do Estado contribuiu para uma reestruturação global da produção, aumentando a incidência em países periféricos e uma baixa industrial nos países centrais, gerando uma conjunção de industrialização e (des)industrialização respectivamente. Rearranjando a manifestação daquilo que entendemos como centro e periferia, primeiro e terceiro mundos, a partir de uma nova divisão internacional do trabalho (SOJA: 1993, p. 95);

24 [d] Geração de uma taxa de declínio de empregos industriais e aumento de postos de trabalho no setor de serviços, com menores salários, ambiente empresarial mal organizado, com menor presença sindical e maior facilidade de manipulação dos empregados, gerando um estreitamento no meio do mercado de trabalho, contratação de mão de obra mais explorada como mulheres e imigrantes.

Logo, os processos selecionados na explicação dessa reestruturação introduzem na paisagem geográfica uma combinação de modos opostos de espacialização, como o desenvolvimento desigual regional, desindustrialização urbana que esvazia antigas concentrações industriais ao passo que ocupas cidades metropolitanas, ou até rurais, que trazem consigo em diferentes níveis o fenômeno da urbanização.

A reestruturação por si só já explica esse esforço capitalista para se manter vigente e é no cerne desse processo histórico-social, que a reestruturação produtiva que surge com a Terceira Revolução Industrial - lógica da microeletrônica, redes informacionais, mundialização do capital e mudança da subjetividade social dentro e fora do ambiente de trabalho - afeta o mundo do trabalho organizado, cada vez mais precarizado. 


\section{Acumulação flexível e a filial Cervejaria Rio De Janeiro}

A partir da revisão teórica acerca dos termos acumulação flexível e reestruturação produtiva-territorial, e mesmo ciente que das dificuldades, polêmicas e limites de ser pensar uma acumulação com características pós-fordistas nas periferias do mundo, foi possível constatar inúmeros pontos de proximidade entre o atual modelo e suas ramificações no contexto social, espacial e econômico com a Ambev. A empresa se mostra no mercado mundial como uma gigante que traz para si a cada dia características da acumulação flexível, mesmo que de maneiras sinuosas; como uma empresa brasileira, num universo de contradições de um país em desenvolvimento, o processo de flexibilidade se deu e ainda se dá de maneira distinta em cada região do país e mesmo do mundo, já que a empresa cada vez mais globalizada, possui plantas industriais em diversos países das Américas. Para fins metodológico-procedimentais, focaremos nossa análise na flexibilidade no "mundo do trabalho" da empresa, no processo de terceirização e na própria turistificação como estratégica de marketing.

\section{Flexibilidade, subjetividades e mundos do trabalho}

Junto às mudanças no chão-da-fábrica, emergem ideologias que atingem o trabalhador, que por sua vez, "flexibilizado", assiste a ampliação das regras e valores na gestão e na manipulação do trabalho baseadas em uma série de inovações organizacionais e sóciometabólicas (captura da subjetividade) dentro da empresa (ALVES, 2007).

A sustentação desses dispositivos técnicos-organizacionais, é amparada pelo engajamento e captura da subjetividade do trabalhador. Dentro desses dispositivos técnicos organizacionais temos as formas de pagamento e remuneração flexível, a terceirização capaz de instaurar uma "produção enxuta" e constituir em torno da firma central (e empresa em rede), uma complexa rede de empreendimentos subcontratados; a organização da produção em grupos de trabalho (team work), as novas técnicas de manipulação gerencial que cobiçam os valores dos colaboradores, suas crenças, sua interioridade e sua personalidade, etc. (ALVES, 1999).

30 A constituição das equipes de trabalho e a empresa em rede são manifestações concretas deste novo trabalhador coletivo. Exige-se, deste modo, cada vez mais, habilidades comunicacionais necessárias para a consecução das redes informacionais que constituem as equipes de trabalho e o trabalho em rede (RAVELLI, 1995). Diante da constante ânsia por expansão no mercado e cumprimento de metas, a empresa aposta pesado na motivação de seus empregados, mas para que os resultados sejam satisfatórios, é necessário um progressivo trabalho psicológico por parte da empresa. Entretanto, esse trabalho se dá de forma velada e os próprios funcionários acreditam que essa política da empresa seja justa, sem muitas vezes refletir sobre como esse ambiente de trabalho pode ser prejudicial para sua saúde. Em entrevista ${ }^{1}$ com uma exfuncionária da empresa (Programa "Jovem Aprendiz"), ela afirma: "a AMBEV é uma empresa, com um leque de oportunidades de crescimento, cada um tem seu cargo, porém o conhecimento adquirido é de diversas áreas, então todos agregam um ao outro com formas diferentes de conhecimento" (Trabalho em Equipe/Team Work).

31 Nesse ambiente em que o trabalhador vive sob constante pressão psicológica e está submetido a uma série de problemas desta ordem, a Ambev disponibiliza o "Espaço 
Saúde"2 levou para dentro da cervejaria o tratamento dos problemas adquiridos pelos funcionários, muitas vezes pelo próprio cotidiano de trabalho. Em entrevista ${ }^{3}$, outro funcionário (operador fabril) relata:

"Trabalhar lá é bom, pelo fato da trilha de carreira, benefícios e uma remuneração acima das outras empresas. $O$ que deixa a desejar é a conciliação entre vida pessoal e trabalho; por exemplo uma folga certa da semana pode ser cancelada se a linha quebrar ou não produzir o necessário para a demanda. $\mathrm{E}$ isso sempre foi assim. $\mathrm{E}$ não vai mudar, porém existem algumas coisas que eles fizeram para amenizar esse impacto, como uma planilha de bancos de hora, priorizando uma data importante e garantindo a folga naquele determinado dia. Outras coisas foram alguns "mimos" colocados dentro da cervejaria, como dentista, médico, fisioterapia, cabeleireiro masculino e feminino, quiropraxia e outras coisas".

Um dos funcionários responsáveis pela visita ressaltou três aspectos de maior relevância na empresa: conhecimento, propósito e autonomia. No primeiro, ele ressaltou a formação e comprometimento dos funcionários para com a empresa, falando brevemente sobre sua formação profissional e seu histórico na Ambev, seu discurso foi bastante pautado na motivação, inovação pessoal do funcionário, mérito, comprometimento a estar sempre superando desafios para cumprir as metas, e crescimento dentro da empresa. Em entrevista ${ }^{4}$ com um funcionário, que desempenha o cargo de promotor externo, colhemos as seguintes afirmações: "trabalhar na Ambev é algo bem desafiador. Todos os dias nos são dadas muitas metas a serem atingidas" e ainda, "nosso foco é nunca estarmos satisfeitos, sempre em busca dos melhores resultados". A luta constante para atingir o mérito - termo que privilegia metas inatingíveis e distancia o horizonte do trabalhador - revela a forma de sempre poder cobrar do funcionário desafios que jamais se esgotam.

A linguagem corporativa ajuda na inserção dessa lógica ao passo que transmite essa ideia de flexibilidade. São "colaboradores" (e não funcionários), supostamente pessoas livres e juridicamente iguais. E o tempo de vida social tende a ser dilacerado pelo tempo de trabalho, de forma totalmente velada (trabalho abstrato, espaço de trabalho e espaço doméstico também se entrecruzam), por meio de

[...] um circuito ideológico de construção de uma nova hegemonia do capital na produção e na vida social. É um construto sinistro que ignora a precariedade e a contingência do novo mundo do trabalho. Ela ignora o dado crucial de que os supostos empreendedores independentes estão subsumidos (e subordinados) às grandes corporações capitalistas, que os submetem aos ciclos incertos dos negócios e ao acaso do jogo do mercado; e que os clientes aos quais os auto-empreendedores vendem seus serviços são eles próprios individualidades de classe, imersos na precariedade e submetidos ao espectro da insolvência. (ALVES, GIOVANNI, 2007, p. 173, grifos nossos)

\section{Flexibilidade e terceirização produtiva}

Outra característica descrita no modelo de acumulação flexível é a tendência em que grandes empresas como a Ambev optem pela terceirização em suas unidades produtivas a fim de baratear os custos e as preocupações com pessoal (direitos trabalhistas, impostos e tributos). Nesse caso, a grande firma conserva um pequeno número de trabalhadores estáveis e em período integral, e o resto do "seu" quadro de trabalhadores é formado por uma massa variável de colaboradores externos, substitutos temporários, prestadores de serviços autônomos entre outros - que em muitos casos possuem altos níveis profissionais, igualmente ao número reduzido de 
trabalhadores estáveis/contratados - que custam muito menos para as grandes empresas (terceirização). Assim,

a firma pode se desincumbir, no que diz respeito a esses externos, de uma parte crescente do custo (do valor) de sua força de trabalho. Ela se desfaz, às expensas deles, dos custos da sua formação contínua, de seu seguro-saúde, de sua pensão. Ela compra seus serviços negociando o preço pela tarefa ou pelo tempo ocupado, põenos em concorrência uns com os outros, atribui-se a possibilidade de fazer variar fortemente o volume de trabalho que lhes demanda sem se preocupar com a duração do trabalho, sem ter de conceder licenças, contratar, indenizar. (GORZ, 2005).

A terceirização em suas unidades produtivas a fim de baratear os custos e as preocupações com pessoal, apresentava limites legais na sua execução, quando as empresas ainda respondiam pela Lei no 6.019/1974 que proibia o uso da mão de obra terceirizada nas chamadas atividades-fim (consideradas primordiais para o funcionamento da empresa) e permitiam a terceirização em atividades-meio (limpeza, alimentação, segurança etc.). A Ambev em sua filial em Agudos-SP (13 km de Bauru) foi condenada a pagar indenização de 1 milhão de reais, reversível ao Fundo de Amparo ao Trabalhador (FAT) ou a entidades indicadas pelo Ministério Público do Trabalho (MPT), autor da ação; por danos morais coletivos ao utilizar mão de obra terceirizada nas atividades-fim da unidade, e a decisão determinou ainda que a ré (Ambev) substituísse a mão de obra terceirizada por trabalhadores diretamente contratados (JORNAL DA CIDADE, 2016).

Porém, em 2017 o então presidente Michel Temer assinou a Lei n. ${ }^{\circ} 13.429$ conhecida como "Lei da Terceirização", que passou a regular o trabalho terceirizado e temporário no Brasil, alterando o texto vigente e permitindo a qualquer empresa contratar um trabalhador independente da atividade que exercerá. Assim, agora é possível ter pessoas que realizem a "atividade fim" de uma empresa, porém sem caracterizar um vínculo com a mesma. Tal decisão configura a atual onda de flexibilidade dos direitos trabalhistas que está em vigor no país.

Durante o trabalho de campo, a impressão do senso comum sobre grandes fábricas caiu por terra, já que mesmo sendo a maior cervejaria da América do Sul, o chão-de-fábrica mostrou-se quase que ausente de funcionários, descrevendo um processo fabril pautado na alta mecanização e abundante uso de tecnologias, onde quase não há contato humano na produção (figura 1): 
Figura : Interior da fábrica

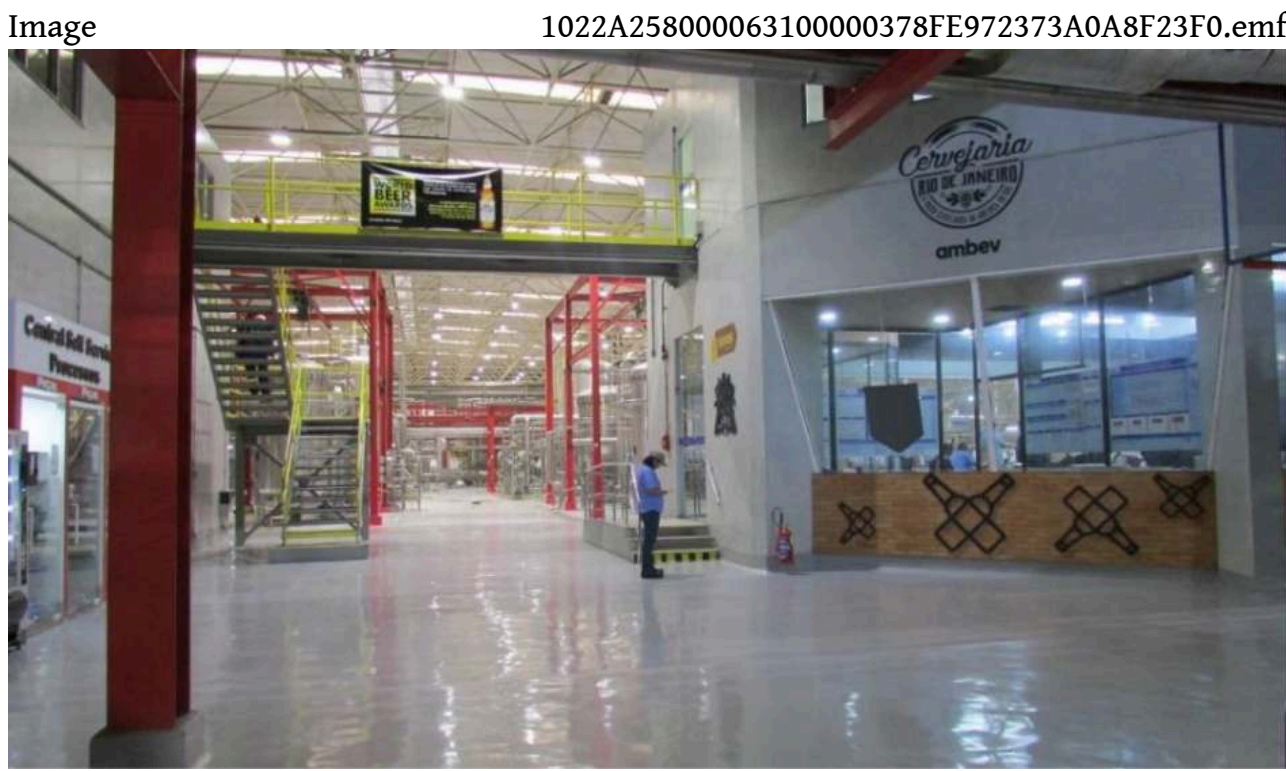

Fonte: Registro de Beatriz Sant'Anna, em 20 de setembro de 2019 (Acervo LAGEP). enxugamento é que se circunscreve nas características de flexibilidade, gera impactos sociais em relação a diminuição de postos de trabalho entre outros fatores que não são amplamente discutidos na vinda de uma grande indústria para determinada localidade. $\mathrm{Na}$ maioria dos casos, como o da Filial Cervejaria Rio de Janeiro de Campo Grande, a escolha da localidade de instalação, além da questão de viabilidade produtiva (água que capta do guandu) e logística (possibilidade de distribuição da produção), poder-se-ia acreditar na geração de empregos e possíveis melhorias infraestruturas dos arredores da fábrica; fato que a cada dia que passa, torna-se controverso pelo esvaziamento do número de vagas pela mecanização e também por que o entorno da fábrica não conta com infraestrutura urbana adequada, pois muitas ruas não são pavimentadas e a presença de uma população bastante pobre nas proximidades é muito presente. Isto nos faz questionar as vantagens da vinda de grandes empresas, muitas vezes com isenções fiscais e financiamentos públicos que não trazem nenhum retorno social local.

\section{Flexibilidade e "turismo de fábrica"}

Em meio a tais questões, o trabalho de campo se mostrou revelador: desde o início, a visita contou com uma evidente atmosfera romantizada da produção e da vida na fábrica, voltada para constante animação do público, onde eram constantemente feitas perguntas de feedback e citados jargões de ânimo para o grupo. A partir disso, com base em Oliveira (2013), a discussão sobre o turismo em fábrica se faz presente em geografia econômica e geografia da indústria, onde a disciplinaridade do mundo da indústria e a 
organicidade de um modelo produtivo, entre o fordismo e a acumulação flexível, em voga na periferia econômica mundial se apresenta.

41 A fábrica passa a ser "higienizada", "turisticada", "fetichizada" e assim ancorada no próprio universo do consumo. Aos olhos dos visitantes, a exploração do trabalho, a produção alienada e a própria forma de angariar lucros se dissolve, afinal, "somente este capitalismo contemporâneo, com suas novas dimensões simbólicas e possibilidades interpretativas, seria capaz de fazer da fábrica um lugar de 'experenciação', com sabores, saberes, aromas, trabalho e lazer combinados" (OLIVEIRA, 2013). Visto que, esse turismo em fábrica tem objetivos bastante claros no que tange o esforço, por vezes disfarçado de transparência, em captar a subjetividade dos consumidores ao mostrar o processo produtivo de forma "aberta", trazendo uma maior aproximação e identificação, que resultam em consumo de seus produtos.

o fenômeno turístico (turismo em fábrica) extravasa o comércio de paisagens naturais simbólicas, históricas, culturais, naturais, exóticas e atinge o cotidiano em suas múltiplas formas. Assim:

Os visitantes são defrontados não somente com este modelo de fábrica emergente: clean, sustentável, com mão-de-obra reduzida e flexível, portando um sistema integrado de visitação turística e venda de produtos, mas com um mundo impossível de ser compreendido sem a utilização de todos os sentidos. Se o "mundo da fábrica", configurado pela hostilidade entre patronato e operariado, recebe em tempos atuais uma reestilização. (OLIVEIRA, 2013)

Os turistas que fazem a visitação da Ambev são conduzidos pelo discurso da empresa, que faz com que esse público releve ou ignore questões como o processo de mais-valia, o método de expropriação de riquezas, a redução do número de empregos ofertados pelo crescente aumento da automação da produção, a política voraz da empresa em bater metas e o uso do trabalho que perpassa o horário e os muros da fábrica. Em entrevista ${ }^{5}$ com uma ex-funcionária que trabalhou na empresa como supervisora, ela relatou a experiência em trabalhar na Ambev como:

"Uma experiência única, com um aprendizado acelerado e muitos desafios diários. Em pouco tempo consegui desenvolver habilidades de liderança, trabalho em equipe e pensamento analítico para tomar decisões sob diferentes situações. A empresa oferece bons benefícios para os funcionários, porém o trabalho acaba sendo com uma carga muito alta e as pessoas acabam tendo que ficar conectadas muito tempo com os problemas da fábrica".

Outro funcionário relatou ${ }^{6}$ :

“É uma empresa bastante agressiva em relação a produtividade né, mas não é ruim de se trabalhar mesmo. Mesmo que nem sempre os seres humanos possam estar constantemente motivados e aptos a cumprir metas o tempo todo. Principalmente os cargos mais altos. Eu participei de algumas reuniões de produtividade e planejamento, o pau canta firme! Discussões e bate bocas enormes! Tudo por uma produtividade melhor. " [...] "Eu já tive um quadro de estresse lá, fiquei uma semana sem reconhecer minha família, só reconhecia minha ex-esposa e minha irmã mais velha. De lá em diante eu decidi não me estressar mais lá. Eu estava com alguns problemas em casa, porém o estopim foi a Ambev."

Assim, a cerveja, produto de enorme adesão de pessoas torna-se nessa turistificação de fábrica um subterfúgio que penetra a subjetividade dos visitantes, que já são Beers Lovers antes mesmo de conhecer a produção de sua bebida, porém saem de lá com a imagem de um processo produtivo e de trabalho um tanto quanto ilusório e maquiado. 


\section{Considerações finais}

Por meio da análise aqui realizada, torna-se evidente a linha comportamental da empresa analisada e suas inúmeras características que a enquadra, com todos os limites do termo, no modelo de acumulação flexível. Neste momento, as corporações emersas em condições de competição cada vez mais acirrada, apostam em racionalizações, reestruturação e intensificação do controle do trabalho. As inovações tecnológicas, automação da produção, busca por novas linhas de produto e nichos de mercado, a dispersão geográfica para localidades onde o controle dos trabalhadores e do trabalho é mais facilitado, principalmente pelo enfraquecimento sindical cada vez mais intenso.

A onda de fusões e medidas para acelerar o tempo de giro do capital também tem ganho destaque na estratégia de grandes empresas para se manterem ativas mesmo em momentos de crise. O capitalismo atual está muito mais submetido a crises e, consequentemente, está sempre procurando se adequar às incertezas e oscilações, gerando novos domínios através de reorganizações no mundo do trabalho e consequentemente mudanças na vida social, onde as pessoas encontram-se constantemente à deriva, tendo sua mão de obra facilmente descartada, substituída e ultrapassada. Pede-se maior qualificação ao passo que a desvalorização do trabalho têm se tornado regra até para os profissionais com títulos, aliado a uma onda de desemprego estrutural que faz com que os empregadores possuam maior vantagem sobre os contratados.

A constante preocupação da cervejaria para se mostrar ao mercado como uma empresa consciente, começa dentro do ambiente de trabalho, onde a Ambev possui uma linguagem dita informal com seus funcionários, ocultando desta forma o controle do tempo de trabalho que perpassa os muros da fábrica, fazendo com que os trabalhadores se sintam responsáveis e culpados a todo momento pelo alcance ou não dos objetivos traçados, fator que é facilmente mascarado pelo ambiente informal, as reuniões e "happy hours" promovidos pela empresa. E essa preocupação, alcança também o mercado consumidor, no qual a empresa tenta alcançar das mais variadas formas, lançando campanhas de marketing que se apropriam de culturas e costumes locais, divulgando em nome da Ambev diversos programas sociais e ambientais, ao passo que não dialoga com a comunidade ao entorno de sua fábrica e se "pinta de verde" a todo momento em discursos sustentáveis, sendo que tais atitudes de redução e reciclagem são vantajosas para o custo de produção de suas bebidas, assim como a adição de ingredientes mais baratos como milho e arroz nas receitas.

A desconcentração se apresenta na dispersão de plantas industriais no território nacional, ao passo que a administração e a concentração de capital se concentra em um grupo minoritário e nas regiões mais ricas do país. A Ambev é sediada em São Paulo e o mercado consumidor que mais gera lucro para a empresa é no eixo sul-sudeste, onde a centralização do capital industrial, bancário e comercial se encontra. Observa-se uma crescente separação entre propriedade e controle, e emerge complexas hierarquias de gerenciamento, facilitadas pelo desenvolvimento científico e tecnológico que possibilita a expansão de impérios econômicos e controle da produção e de mercados no exterior, mediado por uma articulação entre Estado e capital, possibilitando o aumento dos monopólios e estratificação social - fator disfarçado do imaginário das pessoas através de uma cultura ideológica capitalista. 
50 consumo ainda está limitada à chamada, em linhas gerais, classe média, que busca sabores e tipos de cerveja mais "refinados" e consequentemente mais caros, algo que não é realidade da grande parte da população. E ao observar essa busca por outros tipos de cerveja, a Ambev procura expandir seu mercado comprando marcas e/ou desenvolvendo receitas que se adequem a esse modo de consumo emergente.

\section{BIBLIOGRAFIA}

ALVES, Geovanni. Dimensões da Reestruturação Produtiva: Ensaios de sociologia do trabalho. Ed. 2. Londrina: Praxis; Bauru: Canal 6, 2007.

ALVES, Geovanni. Trabalho e mundialização do capital. Londrina: Práxis, 1999

GORZ, André. O Imaterial: Conhecimento, Valor e Capital. São Paulo: Annablume, 2005

HARVEY, David. Condição pós-moderna: uma pesquisa sobre as origens da mudança cultural. Ed 17. São Paulo: Loyola, 1992.

OLIVEIRA, Leandro Dias de. A emersão da região logístico-industrial do Extremo Oeste Metropolitano fluminense: reflexões sobre o processo contemporâneo de reestruturação territorial-produtiva. Espaço e Economia: Revista Brasileira de Geografia Econômica, ano IV, n. 7, julho-dezembro de 2015. Disponível em: http://journals.openedition.org/espacoeconomia/1814. Acesso em: 10 de abril de 2020.

OLIVEIRA, Leandro Dias de. Sabores, Saberes, Trabalho, Lazer: Relato sobre o "Tour Chocolover" na Fábrica de Chocolates Nestlé (Caçapava / SP). Geografia (Londrina), v.22, n.2. p. 103 -115, maio/ ago. 2013.

REVELLI, Marco. Economia e Modello Sociale Nel Passagio tra Fordismo e Toyotismo. In: INGRAO, Pietro e ROSSANDA, Rossana (Orgs.), Appuntamenti di fi nesecolo, Manifestalibri: Roma, 1995.

SENNETT, Richard. A corrosão do caráter: consequências pessoais do trabalho no novo capitalismo. Rio de Janeiro: Record, 2004.

SOJA, Edward. Geografias pós-modernas: a reafirmação do espaço na teoria social crítica. Rio de Janeiro: Jorge Zahar, 1993.

\section{NOTAS}

1. Entrevista realizada dia 24 de setembro de 2019.

2. Juntamente com a Fundação Zerrenner, a Ambev disponibiliza um espaço onde é oferecido aos funcionários fora do expediente de trabalho alguns serviços como dentista, médico, fisioterapia, quiropraxia etc.

3. Entrevista realizada dia 20 de setembro de 2019.

4. Entrevista realizada dia 20 de setembro de 2019.

5. Entrevista realizada dia 23 de setembro de 2019. 


\section{RESUMOS}

O objetivo do presente artigo é realizar uma discussão acerca do modelo de acumulação flexível a partir da filial da Ambev cervejaria Rio de Janeiro, localizada no bairro de Campo Grande, Rio de Janeiro - RJ. A Ambev - American Beverage Company ou Companhia de Bebidas das Américas é uma empresa de capital aberto que surgiu em 1999 através de um longo histórico de fusões, que a faz ser um dos maiores oligopólios do mundo, possuindo uma grande fatia do mercado nacional e internacional de bebidas alcoólicas e não alcoólicas. Neste sentido, a pesquisa refletirá sobre a busca incessante por espaço e consumidores pautada numa política empresarial de penetração na subjetividade de seus funcionários, que trabalham para cumprir metas inalcançáveis; na descentralização de plantas industriais e centralização de poder administrativo e produção altamente tecnológica com a presença cada vez menor de operários no chão de fábrica.

This paper aims to discuss on the model of flexible accumulation looking at the Ambev Brewery branch, located in the neighborhood of Campo Grande, Rio de Janeiro, RJ. The American Beverage Company - Ambev - is a publicly traded company that emerged in 1999 through a long history of mergers, which makes it one of the largest oligopolies in the world, holding an extensive share of the national and international markets for alcoholic and non-alcoholic beverages. This research will reflect on the relentless search for space and consumers, based on a voracious corporate penetration policy in the subjectivity of its employees, who work to achieve unreachable goals; decentralization of industrial plants and centralization of administrative power; and a highly technological production, reducing the presence of workers on the shop floor.

Le but de cet article est de discuter le modèle d'accumulation flexible à partir de la filiale Ambev Cervejaria Rio de Janeiro, située dans le quartier de Campo Grande, Rio de Janeiro - RJ. L'Ambev American Beverage Company ou Companhia de Bebidas das Américas - est une société par actions qui a émergé en 1999 grâce à une longue histoire de fusions, ce qui en fait l'un des plus grands oligopoles au monde, avec une part importante du marché national et international de boissons alcooliques et non alcooliques. En ce sens, l'investigation réfléchira sur la recherche incessante d'espace et de consommateurs guidée par une politique d'entreprise de pénétration de la subjectivité de ses employés, qui travaillent pour atteindre des objectifs inaccessibles ; elle réfléchira aussi sur la décentralisation des installations industrielles et sur la centralisation du pouvoir administratif et de la production hautement technologique avec la diminution de la présence d'ouvriers dans l'usine.

El propósito de este artículo es discutir el modelo de acumulación flexible de la filial empresa Ambev Cervejaria Rio de Janeiro, ubicada en el barrio de Campo Grande, Rio de Janeiro - RJ. La Ambev - American Beverage Company o Companhia de Bebidas das Américas es una empresa que cotiza en bolsa y que surgió en 1999 a través de una larga historia de fusiones, lo que la convierte en uno de los mayores oligopolios del mundo, con una gran participación en el mercado nacional e internacional de bebidas alcohólicas y no alcohólicas. En este sentido, la investigación reflexionará sobre la búsqueda incesante de espacio y consumidores que se guía por una política empresarial voraz de penetrar en la subjetividad de sus trabajadores que trabajan para cumplir objetivos inalcanzables, en la descentralización de plantas industriales y centralización del poder 
administrativo y en la producción altamente tecnológica con un número aún menor de trabajadores en el piso de la fábrica.

\section{ÍNDICE}

Palavras-chave: Ambev Cervejaria Rio de Janeiro, Acumulação Flexível, Trabalho, Reestruturação Produtiva- Territorial.

Palabras claves: Ambev Cervejaria Rio de Janeiro, Acumulación flexible, Trabajo, Reestructuración productivo-territorial.

Keywords: Ambev Brewery Rio de Janeiro, Flexible Accumulation, Work, Productive-Territorial Restructuring

Mots-clés: Ambev Cervejaria Rio de Janeiro, Accumulation flexible, travail, restructuration productive-territoriale.

\section{AUTOR}

\section{BEATRIZ DO NASCIMENTO SANT'ANNA}

Graduada em Geografia pela Universidade Federal Rural do Rio de Janeiro (UFRRJ), campus Seropédica. Membro do Laboratório de Geografia Econômica e Política (LAGEP-UFRRJ), na linha Reestruturação Econômica-Espacial Contemporânea, sob coordenação do Prof. Dr. Leandro Dias de Oliveira. E-mail:ibeatrizsantanna@hotmail.com. 